\title{
Global Potential for Wind-Generated Electricity
}

\section{Citation}

Lu, Xi, Michael B. McElroy, and Juha Kiviluoma. 2009. Global potential for wind-generated electricity. Proceedings of the National Academy of Sciences of the United States of America 106(27): 10933-10938.

\section{Published Version}

http://dx.doi.org/10.1073/pnas.0904101106

\section{Permanent link}

http://nrs.harvard.edu/urn-3:HUL.InstRepos:5029362

\section{Terms of Use}

This article was downloaded from Harvard University's DASH repository, and is made available under the terms and conditions applicable to Other Posted Material, as set forth at http:// nrs.harvard.edu/urn-3:HUL.InstRepos:dash.current.terms-of-use\#LAA

\section{Share Your Story}

The Harvard community has made this article openly available.

Please share how this access benefits you. Submit a story.

Accessibility 


\section{Classification:}

PHYSICAL SCIENCES: Environmental Sciences

Title:

\section{Electricity from Wind: Global Perspective with Detailed Application to the US}

\section{Author Affiliation:}

\section{Xi Lu}

School of Engineering and Applied Science, Harvard University

Cruft Lab 211, 19 Oxford St., MA 02138

Michael B. McElroy

School of Engineering and Applied Science and Department of Earth and Planetary Sciences, Harvard University

100E Peirce Hall, 29 Oxford St., MA 02138

\section{Juha Kiviluoma}

VTT Technical Research Centre of Finland

P.O. Box 1000, 02044 VTT, Finland

\section{Corresponding Author:}

Michael B. McElroy (mbm@seas.harvard.edu)

\section{Key words:}

Electricity from Wind | US and Global Potential |Renewable Energy 


\section{Abstract}

The potential of wind power as a global source of electricity is assessed using winds derived through assimilation of data from a variety of meteorological sources. The analysis indicates that a network of land-based 2.5 MW turbines restricted to non-forested, ice-free, non-urban areas operating at as little as $20 \%$ of their rated capacity, could supply more than 40 times current worldwide consumption of electricity, more than 5 times total global use of energy in all forms. Resources in the contiguous US, specifically in the central plain states, could accommodate as much as 16 times total current demand for electricity in the US. Estimates are given also for quantities of electricity that could be obtained using a network of $3.6 \mathrm{MW}$ turbines deployed in ocean waters with depths less than $200 \mathrm{~m}$ within $50 \mathrm{~nm}$ of closest coastlines. 


\section{Introduction}

Wind power accounted for $30 \%$ of all new electrical capacity added to the US electrical system in 2007 although wind continues to account for a relatively small fraction of the total electricity generating capacity (16.8 GW out of a total of $1075 \mathrm{GW})(1)$. The International Energy Agency in its 2007 alternative Policy Scenario (2) projected the possibility of an 18-fold increase in wind-powered generation of electricity globally by 2030. Most impressive growth was forecast for Europe where, it was suggested, as much as $30 \%$ of total electricity demand could be provided by renewable sources (mainly wind) by 2030. Short et al (3) using the National Renewable Energy Laboratory (NREL)'s WinDs model concluded that wind could account for as much as $25 \%$ of US electricity by 2050 (corresponding to an installed wind capacity of about 300 GW).

Archer and Jacobson (4) estimated that $20 \%$ of the global total wind power potential could account for as much as 123 PWh $\left(1.23 \times 10^{17}\right.$ Watt-hours $)$ of electricity annually (corresponding to annually averaged power production of $14 \mathrm{TW}$ ) equal to seven times total current global consumption of electricity (comparable to present global use of energy in all forms). Their study was based on an analysis of data for the year 2000 from 7753 surface meteorological stations complemented by data from 446 stations for which vertical soundings were available. They restricted their attention to power that could be generated using a network of $1.5 \mathrm{MW}$ turbines tapping wind resources from regions with annually averaged wind 
speeds in excess of $6.9 \mathrm{~m} / \mathrm{s}$ (wind class 3 or better) at an elevation of 80 meters. The meteorological stations employed in their analysis were heavily concentrated in the United States, Europe and Southeastern Asia. Results inferred for other regions of the world are subject as a consequence to considerable uncertainty. In order to estimate wind potential at a particular location, Archer and Jacobson examined six empirical functions to obtain a least square best fit to the wind profile for individual neighboring sounding stations. An inverse square approach was used to average data from the five closest meteorological stations to select the wind profile employed to estimate the power potential at a particular sample location. Archer and Jacobson argued that the estimates for wind power derived using their approach may be conservative on the low side for two reasons: the potential for bias introduced by use of the least square methodology and the fact that the meteorological stations employed in the analysis are not located optimally to capture most favorable wind conditions.

The present study is based on a simulation of global wind fields from Version 5 of the Goddard Earth Observing System Data Assimilation System (GEOS-5 DAS). Winds included in this compilation were obtained by retrospective analysis of global meteorological data using a state-of-the-art weather/climate model incorporating inputs from a wide variety of observational sources (5) including not only surface and sounding measurements as used by Archer and Jacobson (4) but also results from a diverse suite of measurements and observations from a combination of aircraft, balloons, ships, buoys, dropsondes and satellites in short the gamut of observational data employed to provide the world with the best possible 
meteorological forecasts enhanced by application of these data in a retrospective analysis. The GEOS-5 wind field is currently available for the period 2004 to present (Nov. 10, 2008) with plans to extend the analysis 30 years back in time. The GEOS-5 assimilation was adopted in the present analysis in order to take advantage of the relatively high spatial resolution available with this product as compared to the lower spatial resolutions available with alternative products such as ERA-40, NECP II and JRA-25.

GEOS data (including GEOS-5 and previous versions) have been used extensively in a variety of atmospheric chemistry investigations and have proved valuable not only in the interpretation of a wide range of atmospheric chemical measurements (6-8) but also in use of these measurements in an inverse mode to obtain improved estimates for emissions of important atmospheric species (9-11). The GEOS-5 simulation is employed here in a detailed study of the potential for globally distributed wind-generated electricity in 2006 . We expect in the future to extend the analysis of the inter-annual variability of the wind resource over a wider time horizon when the temporally more extensive MERRA database, in development at NASA GMAO, becomes available.

We begin in Section 2 with a description of the methodology adopted for the present study. The land-based turbines envisaged here are assumed to have a rated capacity of $2.5 \mathrm{MW}$ with somewhat larger turbines, $3.6 \mathrm{MW}$, deployed offshore reflecting the greater cost of construction and the economic incentive to deploy larger turbines to capture the higher wind speeds available in these regions. In siting turbines over land, we specifically excluded densely 
populated regions, as well as areas occupied by forests and environments distinguished by permanent snow and ice cover (notably Greenland and Antarctica). Turbines located offshore were restricted to water depths less than $200 \mathrm{~m}$ and to distances within $92.6 \mathrm{~km}$ (50 nautical miles) of shore.

These constraints are discussed in Section 3. Results from the global analysis are presented in Section 4 with a more detailed discussion of results for the US in Section 5. Summary remarks are presented in Section 6.

\section{Methodology}

The GEOS-5 analysis uses a terrain-following coordinate system incorporating 72 vertical layers extending from the surface to a pressure level of $0.01 \mathrm{hPa}$ (an altitude of approximately $78.2 \mathrm{~km}$ ) (5). Individual volume elements are defined by their horizontal boundaries (latitude and longitude) and by the pressures at their top and bottom. The horizontal resolution of the simulation is $2 / 3$-degree longitude by $1 / 2$-degree latitude (equivalent to approximately $66.7 \mathrm{~km}$ by $50.0 \mathrm{~km}$ at mid-latitudes). The model provides 3-dimensional pressure fields at both layer centers and at layer edges in addition to wind speeds (meridional and zonal) and temperatures at the midpoint of individual layers with a time resolution of 6 hours. The three lowest layers are centered at approximate altitudes of $71 \mathrm{~m}, 201 \mathrm{~m}$ and $332 \mathrm{~m}$. The 6 hour data for the three lowest layers are employed in the present analysis using an interpolation scheme indicated as follows to estimate temperatures, pressures and wind speeds at $100 \mathrm{~m}$, the hub height for the 2.5 MW and 3.6 MW turbines considered here. 
Knowing pressures at the lower and upper edges of individual layers together with temperatures and pressures at the mid-points of the layers, altitudes corresponding to the midpoints of the layers are calculated based on an iterative application of the barometric law assuming a linear variation of temperature between the midpoints of individual layers. The barometric law was also used to calculate the pressure at $100 \mathrm{~m}$. Wind speeds and temperatures at $100 \mathrm{~m}$ were computed using a cubic spline fit to data at the midpoints of the three lowest layers.

The kinetic energy of the wind intercepted by the blades of a turbine per unit time (P) depends on the density of the air $(\rho)$, the area swept by the rotor blades $\left(\pi r^{2}\right)$ and on the cube of the wind speed $\left(V^{3}\right)$ reduced by an efficiency or power factor $\left(f_{p}\right)$ according to the formula (12):

$$
E=\frac{1}{2} \rho \pi r^{2} f_{p} V^{8}
$$

The efficiency with which kinetic energy intercepted at any given wind speed is converted to electricity by the turbine depends on details of the turbine design specified by what is referred to as the turbine power curve. Typically, conversion to electricity varies as the cube of the wind speed at low wind speeds, asymptoting to a constant value for moderate to higher wind speeds, dropping to zero at the highest wind speeds when the blades of the turbine are normally feathered to prevent damage. For present purpose, we chose to use 
power curves and technical parameters for $2.5 \mathrm{MW}$ and 3.6 MW turbines marketed by General Electric (http://gepower.com/businesses/ge wind energy/en/index.htm).

These power curves assume an air density of $1.225 \mathrm{~kg} / \mathrm{m}^{3}$ under conditions corresponding to an air temperature of $15{ }^{\circ} \mathrm{C}$ at a pressure of 1 atmosphere (13). To account for the differences in air density at the rotor elevations as compared to this standard, wind speeds in the published power/wind speed curves were adjusted according to the formula

$$
V_{\text {oerrected }}=\left(\frac{D T}{1.22 \mathrm{BE}}\right)^{1 / \mathrm{B}} V_{\text {ortginal }}
$$

where $\mathrm{P}$ and $\mathrm{T}$ identify the air pressures and temperatures at the hub height and $\mathrm{R}$ denotes the atmospheric gas constant, $287.05 \mathrm{~N} \cdot \mathrm{m} /(\mathrm{kg} \cdot \mathrm{K})$ for dry air.

Optimal spacing of turbines in an individual wind farm involves a tradeoff among a number of factors including the costs of individual turbines, costs for site development and costs for laying power cables, in addition to expenses anticipated for routine operations and maintenance $(O \& M)$. Turbines must be spaced to minimize interference in airflow due to interactions among individual turbines. This requires a compromise between the objective to maximize the power generated per turbine and the competing incentive to maximize the number of turbines sited per unit area (14). Restricting downstream inter-turbine wake power loss to less than $20 \%$ requires a downstream spacing of more than seven rotor diameters with cross-wind spacing of more than four diameters $(15,16)$. Applying this constraint to the $2.5 \mathrm{MW}$ 
GE turbines (rotor diameter $100 \mathrm{~m}, \mathrm{r}=50 \mathrm{~m}$ ) requires an inter-turbine areal spacing of $0.28 \mathrm{~km}^{2}$. Similar restrictions apply to the spacing of offshore turbines (rotor diameter $111 \mathrm{~m}, \mathrm{r}=55.5 \mathrm{~m}$ ). For present purposes we assume an area for individual offshore turbines of $5 \times 10$ rotor diameters corresponding to an occupation area per turbine of $0.616 \mathrm{~km}^{2}$. The greater spacing for offshore turbines was selected to ensure that the energy lost due to inter-turbine interference should be limited to $10 \%$ compensating for the presumed higher cost of installation and greater O\&M expense for turbines operating in the more hostile marine environment $(14,15)$. Subject to these constraints, we propose to calculate the electricity that could be generated potentially every six hours on the scale of the individual grid elements defined by the GEOS database (approximately $66.7 \mathrm{~km}$ by $50.0 \mathrm{~km}$ ) subject to the additional spatial limitations identified below.

In addition to providing an estimate for the maximum potential power generation, we propose to evaluate also the power yield expressed as a fraction of the rated power potential of the installed turbines, i.e. to account for the anticipated variability of the wind over the course of a year. This quantity is referred to as the capacity factor (CF), defined by the relation

$$
C F^{\prime}=\frac{B_{\text {rari }}}{B_{\text {ratad }}} \times 100 \%
$$

where $P_{\text {real }}$ denotes the power actually realized (neglecting potential interference between neighboring turbines) while $P_{\text {rated }}$ refers to the power that could have been realized had conditions permitted the turbine to operate at maximum efficiency for $100 \%$ of the time. We 
assume in this context that downtime for maintenance accounts for loss of only a small fraction of the total potential power that could be generated by the installed turbines reflecting the fact that maintenance is normally scheduled for periods of relatively low wind conditions (17). We restrict attention in this analysis to regions with capacity factors greater than $20 \%$.

\section{Geographic Constraints}

The Moderate-Resolution Imaging Spectroradiometer (MODIS) provides a useful record of the spatial distribution of different types of land cover for 2001, with a horizontal resolution approximately $1 \mathrm{~km}$ by $1 \mathrm{~km}$. This record will be used to exclude from our analysis areas classified as forested, areas occupied by permanent snow or ice, areas covered by water and areas identified as either developed or urban.

Wind speeds are generally lower over forested areas reflecting additional surface roughness. Consequently, turbines would have to be raised to a higher level in these environments to provide an acceptable economic return. While it might be reasonable for some regions and for some forest types, we elected for these reasons to exclude forested areas in the present analysis.

The exclusion of water-covered areas is more problematic. Wind speeds are generally higher over water as compared to land. On the other hand, it is more expensive to site turbines in aquatic as compared to terrestrial environments. Public pressures in opposition to the former are also generally more intense, at least in the US. 
Topographic relief data for both land and ocean areas were derived from the Global Digital Elevation Model (GTOPO30) of the Earth Resources Observation and Science (EROS) Data Center of the US Geological Survey (USGS). The spatial resolution of this data source for offshore environments (bottom topography) is approximately $1 \mathrm{~km}$ by $1 \mathrm{~km}$ (18). A number of factors conspire to limit the development of offshore wind farms. Aesthetic considerations for example have limited development of wind resources in the near shore environment in the US although objections to near shore development in Europe appear to have been less influential. There is a need to accommodate also requirements for shipping, fishing and for wildlife reserves and to minimize potential interference with radio and radar installations. Accounting for these limitations, Musial et al $(19,20)$, in a study of offshore wind power potential for the contiguous US, chose to exclude development of wind farms within 5 nautical miles $(\mathrm{nm})(9.3$ $\mathrm{km}$ ) of shore, and to restrict development to $33 \%$ of the available area between 5 and $20 \mathrm{~nm}$ (9.3-37 km) offshore, expanding the potential area available to $67 \%$ between 20 and $50 \mathrm{~nm}$ (37$92.6 \mathrm{~km})$.

For purposes of this study, following Dvorak et al (21), we consider three possible regimes for offshore development of wind power defined by water depths of 0-20 m, 20-50 m and 50-200 m. Somewhat arbitrarily, we limit potential deployment of wind farms to distances within $50 \mathrm{~nm}(92.6 \mathrm{~km})$ of the nearest shoreline, assuming that $100 \%$ of the area occupied by these waters is available for development. 


\section{Wind Power Potential Worldwide}

Approximately $1 \%$ of the total solar energy absorbed by the Earth is converted to kinetic energy in the atmosphere, dissipated ultimately by friction at the Earth's surface $(22,23)$. If we assume that this energy is dissipated uniformly over the entire surface area of the Earth (it is not), this would imply an average power source for the land area of the Earth of approximately $3.4 \times 10^{14} \mathrm{~W}$ equivalent to an annual supply of energy equal to 10,200 Quad $(10,800 \mathrm{EJ})$, approximately 22 times total current global annual consumption of commercial energy. Doing the same calculation for the lower 48 states of the US, would indicate a potential power source of $1.76 \times 10^{13} \mathrm{~W}$ corresponding to an annual yield of 527 Quad (555 EJ), some 5.3 times greater than the total current annual consumption of commercial energy in all forms in the US. Wind energy is not however uniformly distributed over the Earth and regional patterns of dissipation depend not only on the wind source available in the free troposphere but also on the frictional properties of the underlying surface.

We focus here on the potential energy that could be intercepted and converted to electricity by a globally distributed array of wind turbines, the distribution and properties of which were described above. Accounting for land areas we judge to be inappropriate for their placement (forested and urban regions and areas covered either by water or by permanent ice), the potential power source is estimated at 2350 Quad (2470 EJ). The distribution of potential power for this more realistic case is illustrated in Fig. 1. We restricted attention in this analysis to turbines that could function with capacity factors at or greater than $20 \%$. 
Results for the potential electricity that could be generated using wind on a country-bycountry basis are summarized in Fig. 2 A and B for onshore and offshore environments respectively. Placement of the turbines onshore and offshore was restricted as discussed earlier. Table 1 presents a summary of results for the ten countries identified as the largest national emitters of $\mathrm{CO}_{2}$. The data included here refer to national reporting of $\mathrm{CO}_{2}$ emissions and electricity consumption for these countries in 2005. An updated version of the table would indicate that China is now the world's largest emitter of $\mathrm{CO}_{2}$ having surpassed the US in the early months of 2006. Wind power potential for the world as a whole and for the contiguous US is summarized in Table 2.

The results in Table 1 indicate that large-scale development of wind power in China could allow for close to an 18 - fold increase in electricity supply relative to consumption reported for 2005. The bulk of this wind power, $89 \%$, could be derived from onshore installations. The potential for wind power in the US is even greater, 23 times larger than current electricity consumption, the bulk of which, $84 \%$, could be supplied onshore. Results for the contiguous US will be discussed in more detail in the following section. If the top $10 \mathrm{CO}_{2}$ emitting countries were ordered in terms of wind power potential, Russia would rank number 1 , followed by Canada with the US in third position. There is an important difference to be emphasized however between wind power potential in the abstract and the fraction of the resource that is likely to be developed when subjected to realistic economic constraints. Much of the potential for wind power in Russia and Canada is located at large distances from population centers. Given the inevitably greater expense of establishing wind farms in remote 
locations and potential public opposition to such initiatives, it would appear unlikely that these resources will be developed in the near term. Despite these limitations, it is clear that wind power could make a significant contribution to the demand for electricity for the majority of the countries listed in Table 1 , in particular for the four largest $\mathrm{CO}_{2}$ emitters - China, the US, Russia and Japan. It should be noted, however, the resource for Japan is largely confined to the offshore area, $82 \%$ of the national total. To fully exploit these global resources will require inevitably, significant investment in transmission systems capable of delivering this power to regions of high load demand.

The electricity that could be generated potentially on a global basis using wind, displayed as a function of an assumed capacity factor cutoff on installed turbines, is presented in Fig. $3 \mathrm{~A}$ and $\mathrm{B}$. Fig for onshore and offshore environments respectively. The results in Fig. $3 \mathrm{~A}$ suggest that total current global consumption of electricity could be supplied by wind while restricting installation of land based turbines to regions characterized by most favorable wind conditions, regions where the turbines might be expected to function with capacity factors greater than $53 \%$. If the cutoff capacity factor were lowered to $36 \%$, the energy content of electricity generated using wind with land based turbines globally would be equivalent to total current global consumption of energy in all forms. Cutoff capacity factors needed to accommodate similar objectives using offshore resources would need to be reduced as indicated in Fig. 3B. To place these considerations in context, we would note that capacity factors realized by turbines installed most recently in the US (in 2004 and 2005) have averaged close to $36 \%(24)$. 


\section{Wind Power Potential for the US}

An estimate of the electricity that could be generated for the contiguous US on a monthly basis (subject to the siting and capacity limitations noted above) is illustrated for both onshore and offshore environments in Fig. 4. Results presented here were computed using wind data for 2006. Not surprisingly, the wind power potential for both environments is greatest in winter, peaking in January, lowest in summer, with a minimum in August. Onshore potential for January, according to the results presented in Fig. 4, exceeds that for August by a factor of 2.5: the corresponding ratio computed for offshore locations is slightly larger, 2.9.

Fig. 4 includes also monthly data for consumption of electricity in the United States during 2006. Demand for electricity exhibits a bimodal variation over the course of a year with peaks in summer and winter, minima in spring and fall. Demand is greatest in summer during the air conditioning season. Summer demand exceeds the minimum in spring/fall demand typically by between 25 and $35 \%$ on a US national basis depending on whether summers are unusually warm or relatively mild. The correlation between the monthly averages of wind power production and electricity consumption is negative. Very large wind power penetration can produce excess electricity during large parts of the year. This situation could allow options for the conversion of electricity to other energy forms. Plug-in hybrid electric vehicles, for example could take advantage of short term excesses in electricity system, while energy rich chemical species such as $\mathrm{H}_{2}$ could provide a means for longer term storage. 
Potential wind generated electricity available from onshore facilities on an annually averaged state-by-state basis is presented in Fig. 5A. Note the high concentration of the resource in the central plains region extending northward from Texas to the Dakotas, westward to Montana and Wyoming and eastward to Minnesota and lowa. The resource in this region, as illustrated in Fig. 5B, is significantly greater than current local demand. Important exploitation of this resource will require, however, significant extension of the existing power transmission grid. Expansion and upgrading of the will be required in any event to meet anticipated future growth in electricity demand. It will be important in planning for this expansion to recognize from the outset the need to accommodate contributions of power from regions rich in potential renewable resources, not only wind but also solar. The additional costs need not, however, be prohibitive (24). ERCOT, the operator responsible for the bulk of electricity transmission in Texas, estimates the extra cost for transmission of up to $4.6 \mathrm{GW}$ of windgenerated electricity at about $\$ 180$ per kW, approximately $10 \%$ of the capital cost for installation of the wind power generating equipment (25).

An important issue relating to the integration of electricity derived from wind into a grid incorporating contributions from a variety of sources relates to the challenge of matching supply with load demand incorporating a contribution to supply that is intrinsically variable both in time and space and subject to prediction errors. This challenge can be mitigated to some extent if the variations of wind sources contributing to an integrated transmission grid from different regions are largely uncorrelated. An anomalously high contribution from one region can be compensated in this case by an anomalously low contribution from another. To 
investigate the significance of this potential compensation, we examined the covariance of wind resources from three specific regions, one in Montana, the second in Minnesota, the third in Texas, as indicated in Fig. 6. Analysis of 6-hour averaged potential wind generated supplies of electricity from the three regions over the four seasons, winter, spring, summer and fall, yielded the results summarized in Table 3. Contributions from the three regions are essentially uncorrelated during the winter months (October through March) with $r$ values of less than 0.07 . Correlation coefficients ( $r$ values), however, are relatively high in summer (July through September) with values ranging from 0.28 (Montana versus Texas) to 0.37 (Montana versus Minnesota) with intermediate values in spring. The analysis suggests that wind power could make a relatively reliable contribution to anticipated base load demand in winter. It may be more difficult to incorporate wind power resources into projections of base load demand for other seasons, particularly for summer.

\section{Concluding Remarks}

The GEOS-5 winds employed here were obtained through assimilation of meteorological data from a variety of sources, in combination with results from an Atmospheric General Circulation Model (AGCM). Transport in the boundary layer was treated using two different formalisms, one applied under conditions when the boundary layer was stable, the other under conditions when the boundary layer was either unstable or capped by clouds. The variation of wind speed with altitude was calculated in the present study using a cubic spline fit to the three lowest layers (central heights of $71 \mathrm{~m}, 201 \mathrm{~m}$ and $332 \mathrm{~m}$ ) of the GEOS-5 output to estimate 
wind speeds at the rotor heights of the turbines considered here $(100 \mathrm{~m})$. Wind speeds so calculated were used in deriving all of the results presented above.

The rotors of the turbines modeled in this study are of sufficient size that as the blades rotate they traverse significant portions of the two lowest layers of the GEOS-5 simulated atmosphere. Use of wind speed for a single level $(100 \mathrm{~m})$ must be consequently subject to some uncertainty. To assess this uncertainty we explored results derived using an alternate approach. The power intercepted by the blades of the rotors passing through the separate layers was calculated initially on the basis of the reported average wind speeds for the involved layers. Adopting a typical value of about $135 \mathrm{~m}$ for the height of the boundary between the first two layers, given a rotor diameter of $100 \mathrm{~m}$ as appropriate for the assumed onshore turbines, it follows that $99 \%$ of the area swept out by the rotors would intercept air from the first layer, with only $1 \%$ encountered in the second layer. The power intercepted by the rotors may be calculated in this case by averaging appropriately the power intercepted in the two layers. Implementing this approach yielded results that differed typically by less than $15 \%$ for the onshore results presented above, by less than $7 \%$ for the offshore results.

The GEOS-5 data had a spatial resolution of approximately $66.7 \mathrm{~km} \times 50.0 \mathrm{~km}$. It is clear that wind speeds can vary significantly over distances much smaller than the resolution of the present model in response to changes in topography and to changes in land cover (affected in both cases by variations in surface roughness). In general, we expect the electricity yield computed using a low-resolution model to underestimate rather than overestimate what would 
be calculated using a higher resolution model. The GEOS-5 data are expected to provide a useful representation of winds on a synoptic scale as required for example to describe the transport between adjacent grid elements. They would not be expected to account for sub-grid scale variations in wind speeds even though the latter might be expected, at least under some circumstances, to make a significant contribution to the potentially available wind power. To test this hypothesis we explored the implications of a high-resolution wind atlas available for an altitude of 100 m for Minnesota (26).

We distinguished four classes of land cover, forested areas, lakes, vegetated areas (mainly cropland) and regions classified as either urban or built-up. Table 4 presents a comparison of wind speeds at $100 \mathrm{~m}$ implied by the high-resolution atlas with results from GEOS-5. It includes all four surface classifications for conditions of maximum, minimum and average wind. The results for GEOS-5 presented in Table 4 reflect an average of wind speeds derived for the 4-year period 2004-2007. Wind speeds indicated by the high-resolution database are higher in all cases than the wind speeds indicated by GEOS-5, supporting our hypothesis. The close association of wind speed with surface land classification implied by the high resolution Minnesota wind atlas suggests that land classification data could provide a useful basis for at least a preliminary downscaling of the relatively coarse spatial resolution of the potential wind resources in the present study.

We elected in this study to exclude forested, urban, permanently ice covered and inland water regions. Given the relatively coarse spatial resolution of the GEOS-5 database, it is 
possible that this approach may have failed to identify localized environments where wind resources may be unusually favorable and where investments in wind power could provide an acceptable economic return. To explore this possibility, we developed a global land-based map of the efficiencies with which turbines with rotors centered at $100 \mathrm{~m}$ might be capable of converting wind energy to electricity. We included all land areas with the exception of regions identified as permanently ice-covered (notably Greenland and Antarctica). Results, stated in terms of relevant capacity factors, are presented in Fig. 7. Regions with particularly favorable capacity factors, even though forested, urban or occupied by extensive bodies of inland waters, might be considered as potential additional targets for development.

It is apparent, for example, that the low resolution GEOS-5 record underestimates the wind resource available in Spain and Portugal (a consequence most likely of the complex terrains present in these regions). Sweden is another example where wind resources indicated using an available high resolution wind atlas (27) are significantly higher than those implied by GEOS-5. The discrepancy in this case may be attributed to the extensive forest cover of the region and to the a priori decision to neglect such regions in the present global study. Assessment of the potential of mountainous or hilly regions is also problematic. On average, wind speeds in these regions may be relatively low. Particularly favorable conditions may exist, however, on mountain ridges or in passes through mountainous regions. The Appalachian mountain range in the US offers a case in point. In general the low-resolution results appear to slightly overestimate wind resources in regions of flat terrain, while underestimating the potential for regions defined by more complex topography. 
The analysis in this paper suggests that a network of land-based $2.5 \mathrm{MW}$ turbines operating at as little as $20 \%$ of rated capacity, confined to non-forested, ice-free regions would be more than sufficient to account for total current and anticipated future global demand for electricity. The potential for the US could amount to more than 16 times current consumption. Important additional sources of electricity could be obtained by deploying wind farms in nearshore shallow water environments.

An extensive deployment of wind farms may be considered as introducing an additional source of atmospheric friction. For example, if the entire current demand for electricity in the US were to be supplied by wind, the sink for kinetic energy associated with the related turbines would amount to approximately $6 \%$ of the sink due to surface friction over the entire contiguous US land area, $11 \%$ for the region identified as most favorable for wind farm development (the region indicated in red in Fig. 5A defined by wind resources greater than 280 TWh). The potential impact of major wind electricity development on the circulation of the atmosphere has been investigated in a number of recent studies $(28,29)$. These studies suggest that high levels of wind development as contemplated here could result in significant changes in atmospheric circulation even in regions remote from locations where the turbines are deployed. They indicate that global dissipation of kinetic energy is regulated largely by physical processes controlling the source rather than the sink. An increase in friction contributed due to the presence of the turbines is likely to be compensated by a decrease in dissipation by friction elsewhere. Global average surface temperatures they suggest are not expected to change significantly although temperatures at higher latitudes may be expected to 
decrease to a modest extent due to reduction in the efficiency of meridional heat transport (offsetting the additional warming anticipated for this environment due to the build-up of greenhouse gases). In ramping up exploitation of wind resources in the future it will be important to consider the changes in wind resources expected to result from the potential deployment of a large number of turbines in order to more reliably predict the economic return expected to be realized from such deployment. 


\section{Acknowledgement:}

The GEOS-5 data were provided by Mary C. Greene from NASA GES DISK. We are indebted to James G. Anderson, Ralph Cicerone, Philippe Le Sager, Jintai Lin, Chris Nielsen, Yuxuan Wang and three anonymous referees for comments that markedly improved the quality of this final product. Thanks also to Jeff Blossom, Guoping Huang and Sumeeta Srinivasan for their advice on GIS applications. This research was supported by the National Science Foundation, grant ATM-0635548. 


\section{References:}

1. EIA (2008) Short-Term Energy Outlook /STEO Table Browser (Energy Information Administration (EIA), Washington, DC) http://tonto.eia.doe.gov/cfapps/STEO_Query/.

2. IEA ed. (2007) World Energy Outlook 2007: China and India Insights (World Energy Outlook) (oecd publishing; 1 edition (November 23, 2007)).

3. Short, W., Blair, N., Heimiller, D., \& Singh, V. (2003) Modeling the Long-Term Market Penetration of Wind in the United States in WindPower 2003 Conference (AWEA, Austin, Texas)

4. Archer, C. L. \& Jacobson, M. Z. (2005) Evaluation of global wind power J. Geophys. Res. 110.

5. Rienecker, M. M., Suarez, M. J., Todling, R., Bacmeister, J., Takacs, L., Liu, H.-C., Gu, W., Sienkiewicz, M., Koster, R. D., R. Gelaro, I. S., et al. (2007) The GEOS-5 Data Assimilation SystemDocumentation of Versions 5.0.1, 5.1.0, and 5.2.0.(Draft) in Technical Report Series on Global Modeling and Data Assimilation, ed. Suarez, M. J. (NASA)

6. Wang, Y., McElroy, M. B., Martin, R. V., Streets, D. G., Zhang, Q., \& Fu, T.-M. (2007a) Seasonal variability of NOx emissions over east China constrained by satellite observations: Implications for combustion and microbial sources J. Geophys. Res. 112, D06301, doi:10.1029/2006JD007538

7. Zhang, L., Jacob, D. J., Boersma, K. F., Jaffe, D. A., Olson, J. R., Bowman, K. W., Worden, J. R., Thompson, A. M., Avery, M. A., Cohen, R. C., et al. (2008) Transpacific transport of ozone pollution and the effect of recent Asian emission increases on air quality in North America: an integrated analysis using satellite, aircraft, ozonesonde, and surface observations Atmos. Chem. Phys. 8,6117-6136, 2008.

8. Boersma, K. F., Jacob, D. J., Eskes, H. J., Pinder, R. W., Wang, J., \& der, R. J. v. (2008) Intercomparison of SCIAMACHY and OMI tropospheric NO2 columns: Observing the diurnal evolution of chemistry and emissions from space J. Geophys. Res.

9. Wang, Y., McElroy, M. B., Boersma, K. F., Eskes, H. J., \& Veefkind, J. P. (2007b) Traffic restrictions associated with the Sino-African summit:Reductions of NOx detected from space Geophys. Res. Lett 34, L08814, doi:10.1029/2007GL029326.

10. Tanimoto, H., Sawa, Y., Yonemura, S., Yumimoto, K., Matsueda, H., Uno, I., Hayasaka, T., Mukai, H., Tohjima, Y., Tsuboi, K., et al. (2008) Diagnosing recent CO emissions and ozone evolution in East Asia using coordinated surface observations, adjoint inverse modeling, and MOPITT satellite data Atmos. Chem. Phys. 8, 3867-3880.

11. Wang, Y. X., McElroy, M. B., Wang, T., \& Palmer, P. I. (2004) Asian emissions of CO and NOx: Constraints from aircraft and Chinese station data J. Geophys. Res. 109, D24304, doi:10.1029/2004JD005250. 
12. Leithead, W. E. (2007) Wind energy Phil. Trans. R. Soc. A 365, 957-970, doi: 910.1098/rsta.2006. 1955.

13. IEC (2005) Wind turbines - Part 12 - 1: Power performance measurements of electricity producing wind turbines, ed. Commission, I. E. (NYSE: IHS)

14. Dhanju, A., Whitaker, P., \& Kempton, W. (2008) Assessing offshore wind resources: An accessible methodology Renewable Energy 33, 55-64,doi:10.1016/j.renene.2007.1003.1006.

15. Masters, G. M. (2004) Renewable and Efficient Electric Power Systems (John Wiley \& Sons, Inc., Hoboken, New Jersey).

16. Jacobson, M. Z. \& Masters, G. M. (2001) Exploiting Wind Versus Coal Science 293, 14381438,DOI: $1410.1126 /$ science.1063376.

17. Larsen, J. H. M., Soerensen, H. C., Christiansen, E., Naef, S., \& Vølund, P. (2005) Experiences from Middelgrunden $40 \mathrm{MW}$ Offshore Wind Farm in Copenhagen Offshore Wind Conference (Vestas, Copenhagen)

18. USGS (2006) Global Digital Elevation Model(GTOPO30). 30-Arc Seconds (US Geological Survey, Center for Earth Resources Observation and Science (EROS), Sioux Falls, South Dakota) http://eros.usgs.gov/.

19. Musial, W. \& Butterfield, S. (2004) Future for Offshore Wind Energy in the United States in EnergyOcean 2004 (Palm Beach, Florida)

20. Musial, W. (2005) Offshore Wind Energy Potential for the United States in Wind Powering America-Annual State Summit (Evergreen Lake House, Evergreen Colorado)

21. Dvorak, M. J., Jacobson, M. Z., \& Archer, C. L. (2007) California Offshore Wind Energy Potential in Wind Power 2007: American Wind Energy Association Windpower 2007 Conference \& Exhibition (AWEA, Los Angeles, CA)

22. Lorenz, E. N. (1967) The Nature and Theory of the General Circulation of the Atmosphere (World Meteorological Organization, Geneva, Switzerland).

23. Peixoto, J. P. \& Oort, A. H. (1992) Physics of Climate (New York: Institute of Physics).

24. DOE (2008) $20 \%$ Wind Energy by 2030 , Increasing Wind Energy's Contribution to US Electricity Supply http://www.nrel.gov/docs/fy08osti/41869.pdf.

25. ERCOT (2006) Analysis of Transmission Alternatives for Competitive Renewable Energy Zones in Texas (Electric Reliability Council of Texas)

http://www.ercot.com/news/presentations/2006/ATTCH_A_CREZ_Analysis_Report.pdf.

26. Minnesota DOC (2008) 2006 Wind Map GIS Files (Minnesota Department of Commerce) http://www.state.mn.us. 
27. Bergström, H. (2007) Vindpotentialen I Sverige på 1 km-skala (Wind power potential in Sweden at $1 \mathrm{~km}$ scale) (Air, Water and Landscape Sciences; University of Uppsala), p. 18

28. DANIEL B. KIRK-DAVIDOFF, D. W. K. (2008). On the Climate Impact of Surface Roughness Anomalies." JOURNAL OF THE ATMOSPHERIC SCIENCES 65(7): 20

29. David W. Keith, J. F. D., David C. Denkenberger, Donald H. Lenschow, Sergey L. Malyshevr, Stephen Pacalar, and Philip J. Rasch (2004). The influence of large-scale wind power on global climate Proc. Natl. Acad. Sci. USA 101(46): 6 
Fig. 1. Global distribution of annual average onshore wind power potential $\left(W / \mathrm{m}^{2}\right)$ for 2006 accounting for spatial limitation on placement as discussed in the text without limitations on potential realizable capacity factors.

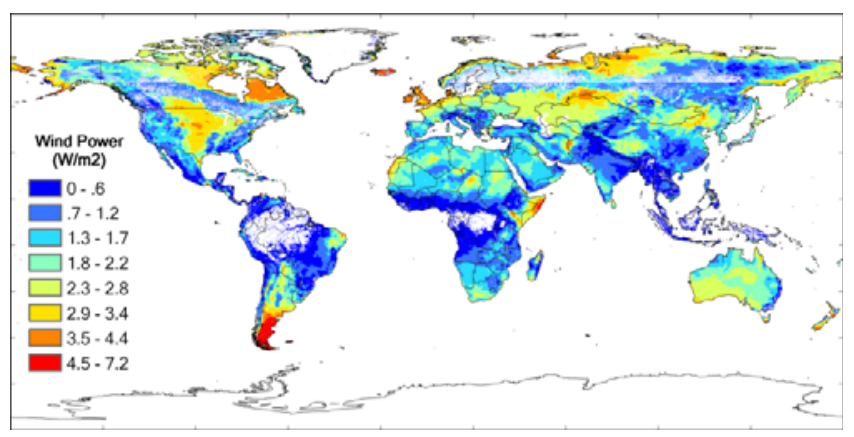


Fig. 2. Annual wind energy potential country by country, restricted to installations with capacity factors greater than $20 \%$ with siting limited as discussed in the Text: (A) Onshore, (B) Offshore.

(A)

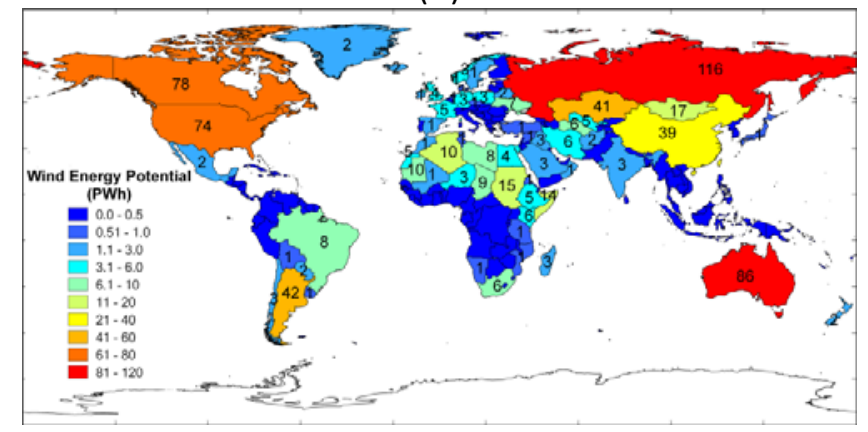

(B)

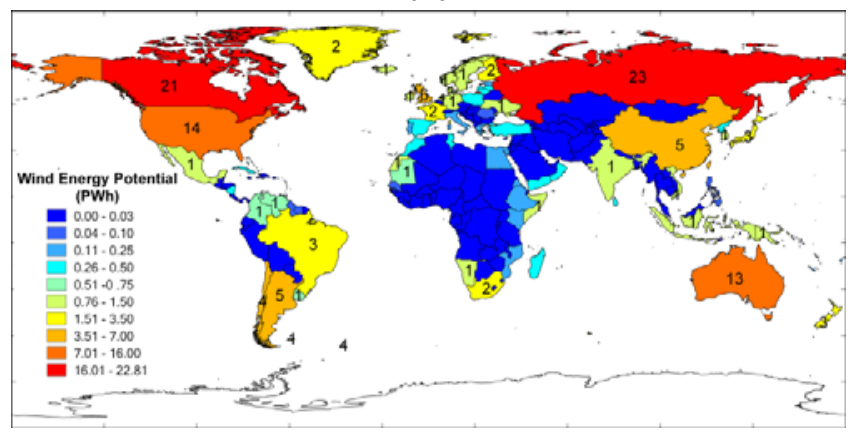


Fig. 3. Annual wind energy potential as a function of assumed limits on capacity factors. Results corresponding to the capacity factor limit of $20 \%$ assumed in this study all indicated by $*$ : (A) Global onshore, (B) Global offshore

(A)

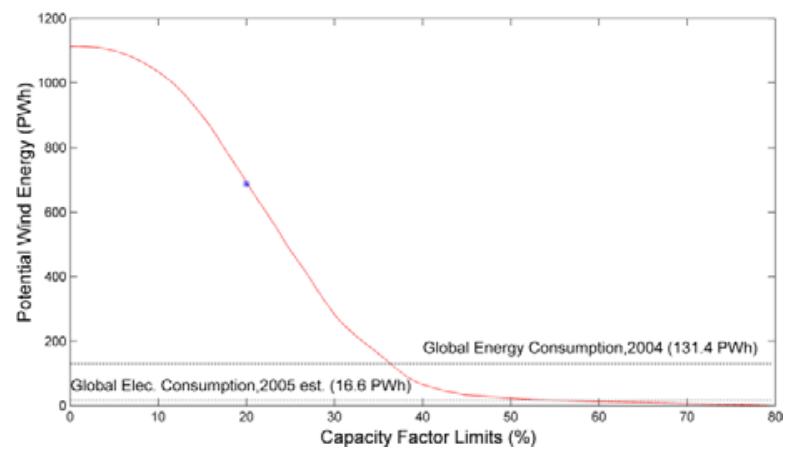

(B)

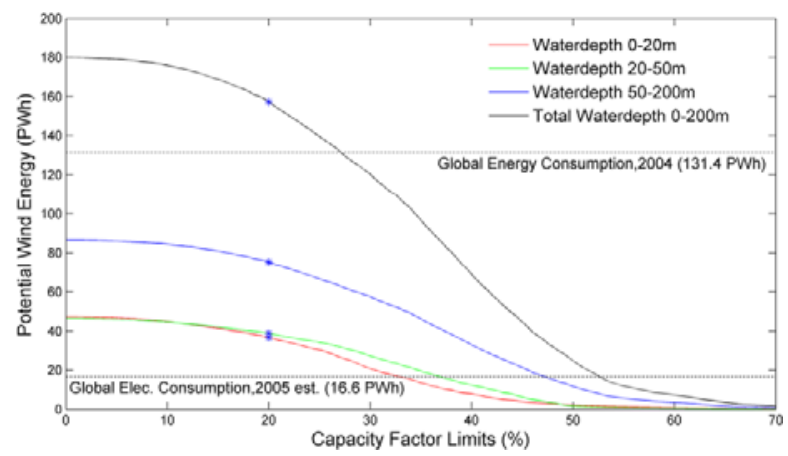


Fig. 4. Monthly wind energy potential for the contiguous US in 2006 and monthly electricity consumption for the entire US

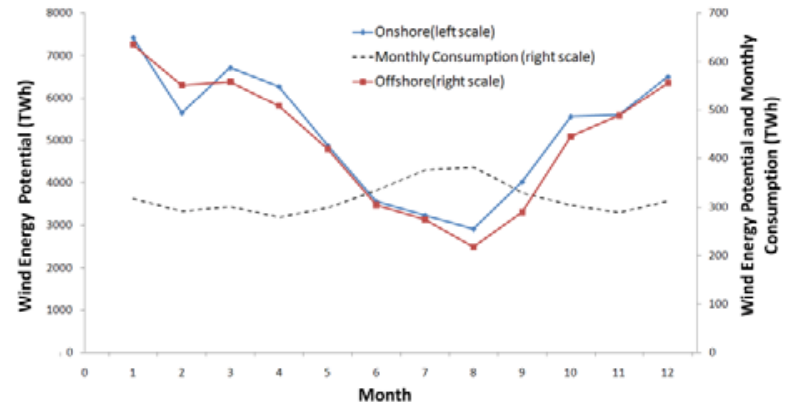


Fig. 5. (A) Annual onshore wind energy potential on a state-by-state basis for the contiguous US (B) Same with A, but expressed as fraction of total electricity retail sales in the states (2006). For example: the potential source for North Dakota exceeds current total electricity retail sales in that State by a factor of 360 .

(A)

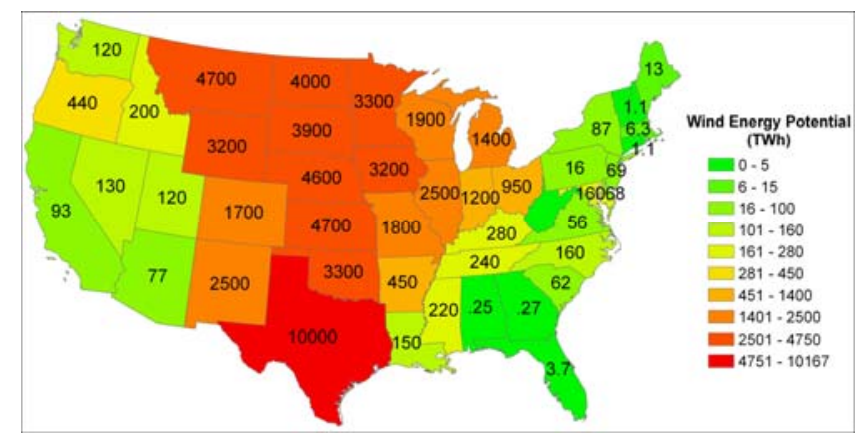

(B)

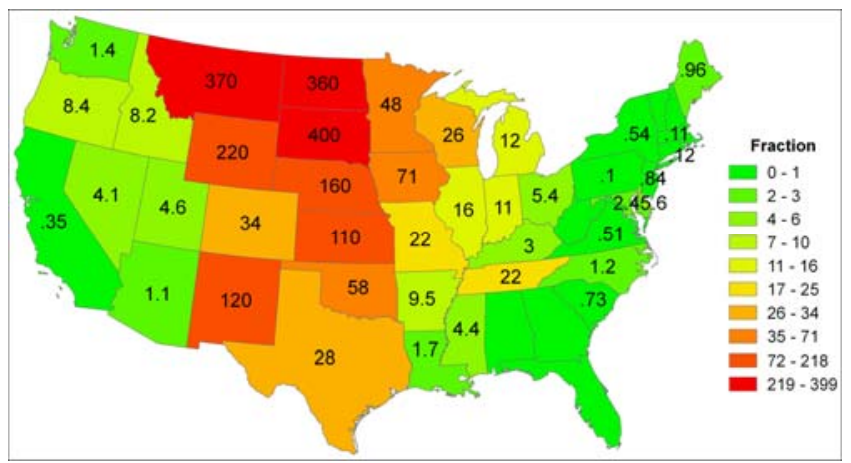

Note: Data source for total electricity retail sales: http://www.eia.doe.gov 
Fig. 6. Locations of regions in Montana, Minnesota and Texas selected to explore the spatial correlation of wind resources.

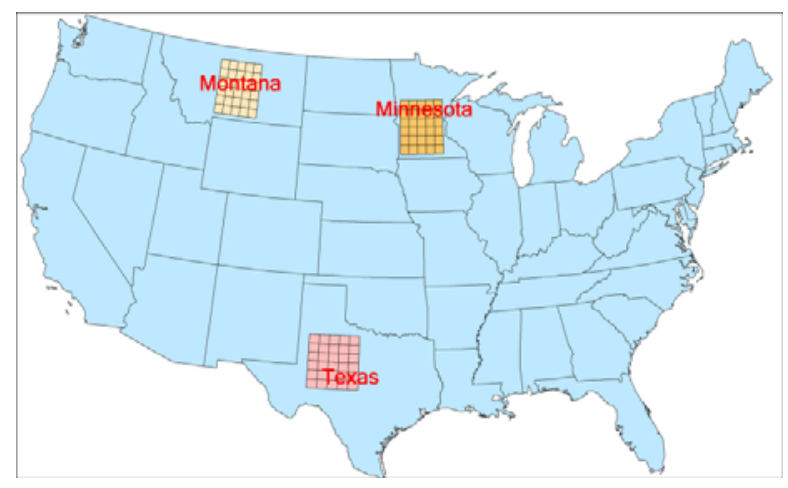

Fig. 7. Global distribution of onshore capacity factor (\%) for winds at 100 meters with exclusion of permanent snow/ice covered areas such as Antarctic and Greenland.

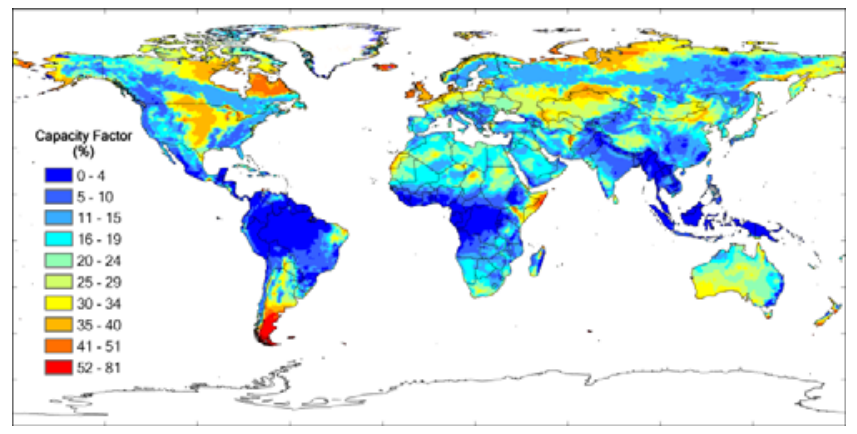


Table 1. Annual wind energy potential, $\mathrm{CO}_{2}$ emissions, and current electricity consumption for the top $10 \mathrm{CO}_{2}$ emitting countries

\begin{tabular}{|l|l|r|r|r|r|r|}
\hline No & Country & \multicolumn{1}{|c|}{$\begin{array}{c}\mathrm{CO}_{2} \text { emission } \\
\left.\text { (million tonnes } \mathrm{CO}_{2}\right)\end{array}$} & $\begin{array}{c}\text { Elec. Consumption } \\
(\mathrm{TWh})\end{array}$ & \multicolumn{3}{|c|}{ Potential Wind Energy (TWh) } \\
\cline { 5 - 7 } & & 5956.98 & & Onshore & \multicolumn{1}{c|}{ Offshore } & \multicolumn{1}{c|}{ Total } \\
\hline 1 & United States & 5607.09 & 3815.9 & 74000 & 14000 & 89000 \\
\hline 2 & China & 1696.00 & 2398.5 & 39000 & 4600 & 44000 \\
\hline 3 & Russia & 1230.36 & 779.6 & 120000 & 23000 & 140000 \\
\hline 4 & Japan & 1165.72 & 974.1 & 570 & 2700 & 3200 \\
\hline 5 & India & 844.17 & 488.8 & 2900 & 1100 & 4000 \\
\hline 6 & Germany & 631.26 & 545.7 & 3200 & 940 & 4100 \\
\hline 7 & Canada & 577.17 & 540.5 & 78000 & 21000 & 99000 \\
\hline 8 & United Kingdom & 499.63 & 348.6 & 4400 & 6200 & 11000 \\
\hline 9 & South Korea & 466.64 & 352.2 & 130 & 990 & 1100 \\
\hline 10 & Italy & 307.5 & 250 & 160 & 410 \\
\hline
\end{tabular}

Note: $\mathrm{CO}_{2}$ emission and electricity consumption for 2005, data source from EIA (http://tonto.eia.doe.gov/country/index.cfm).

Table 2. Annual wind energy potential for installations onshore and offshore for the world as a whole and for the contiguous US. Analysis assumes loss of $20 \%$ and $10 \%$ of potential power for onshore and offshore respectively due to inter-turbine interference.

\begin{tabular}{|c|c|c|c|c|c|}
\hline \multirow{2}{*}{\multicolumn{2}{|c|}{ Areas }} & \multicolumn{2}{|c|}{ World Wide } & \multicolumn{2}{|c|}{ Contiguous US } \\
\hline & & No CF limitation & $20 \%$ CF limitation & No CF limitation & $20 \%$ CF limitation \\
\hline \multicolumn{2}{|c|}{ Onshore Areas (PWh) } & 1100 & 690 & 84 & 62 \\
\hline \multirow{3}{*}{$\begin{array}{l}\text { Offshore } \\
\text { Areas } \\
\text { (PWh) }\end{array}$} & $0-20 \mathrm{~m}$ & 47 & 42 & 1.9 & 1.2 \\
\hline & $20-50 \mathrm{~m}$ & 46 & 40 & 2.6 & 2.1 \\
\hline & $50-200 \mathrm{~m}$ & 87 & 75 & 2.4 & 2.2 \\
\hline \multicolumn{2}{|c|}{ Total (PWh) } & 1300 & 840 & 91 & 68 \\
\hline
\end{tabular}

Note: All data assume offshore location distance within 50 nautical miles (or $92.6 \mathrm{~km}$ ) of the nearest shoreline. 
Table 3. Correlations of wind power potential between selected regions of Montana (MT), Minnesota (MN) and Texas (TX) in different seasons for 2006

\begin{tabular}{|c|c|c|c|c|}
\hline $\begin{array}{c}\text { Correlation } \\
\text { Coefficient (r) }\end{array}$ & Jan. - Mar. & Apr. - Jun. & Jul. - Sep. & Oct. - Dec. \\
\hline MN-MT & 0.027 & 0.11 & 0.37 & -0.15 \\
\hline MN-TX & 0.069 & 0.29 & 0.29 & -0.060 \\
\hline MT-TX & 0.065 & 0.26 & 0.28 & -0.0024 \\
\hline
\end{tabular}

Table 4. Comparison of average $100 \mathrm{~m}$ wind speeds for the 4 year period 2004-2006 obtained using GEOS-5 with data from the local wind atlas (LWA) (10 year average) for Minnesota

\begin{tabular}{|l|l|l|l|l|l|l|}
\hline \multirow{2}{*}{ Land Type } & \multicolumn{2}{|l|}{ Max (m/s) } & \multicolumn{2}{l|}{ Min(m/s) } & \multicolumn{2}{l|}{ Mean(m/s) } \\
\cline { 2 - 7 } & LWA & G5 & LWA & G5 & LWA & G5 \\
\hline Forest & 8.7 & 7.6 & 5.5 & 4.9 & 7.4 & 6.3 \\
\hline Lake & 9.2 & 7.6 & 5.5 & 4.9 & 7.9 & 6.8 \\
\hline Vegetation* & 9.4 & 7.6 & 5.7 & 4.9 & 8.2 & 7.2 \\
\hline Urban/Built up & 8.7 & 7.5 & 5.9 & 5.2 & 7.5 & 7.0 \\
\hline Overall & 9.4 & 7.6 & 5.4 & 4.9 & 8.0 & 6.9 \\
\hline
\end{tabular}

Note: Vegetation refers to non-forested areas occupied mainly by cropland. 